\title{
Retinal Proteomics of a Mouse Model of Dystroglycanopathies Reveals Molecular Alterations in Photoreceptors
}

\author{
Mary Luz Uribe,* José Martín-Nieto, Cristina Quereda, Marcos Rubio-Fernández, Jesús Cruces, \\ George M. C. Janssen, Arnoud H. de Ru, Peter A. van Veelen, and Paul J. Hensbergen*
}

Cite This: J. Proteome Res. 2021, 20, 3268-3277

Read Online

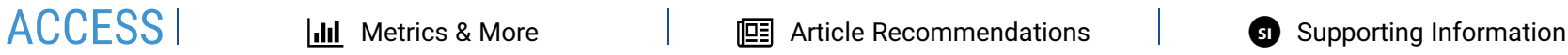

ABSTRACT: Mutations in the POMT1 gene, encoding a protein $O$-mannosyltransferase essential for $\alpha$-dystroglycan ( $\alpha$-DG) glycosylation, are frequently observed in a group of rare congenital muscular dystrophies, collectively known as dystroglycanopathies. However, it is hitherto unclear whether the effects seen in affected patients can be fully ascribed to $\alpha$-DG hypoglycosylation. To study this, here we used comparative mass spectrometry-based proteomics and immunofluorescence microscopy and investigated the changes in the retina of mice in which Pomt 1 is specifically knocked out in photoreceptor cells. Our results demonstrate significant proteomic changes and associated structural alteration in photoreceptor cells of Pomt $1 \mathrm{cKO}$ mice. In addition to the effects related to impaired $\alpha$-DG $O$-mannosylation, we observed morphological alterations in the outer segment that are associated with dysregulation of a relatively understudied POMT1 substrate (KIAA1549), BBSome proteins, and retinal stress markers. In conclusion, our study provides new hypotheses to explain the phenotypic changes that are observed in the retina of patients with dystroglycanopathies.

KEYWORDS: mass spectrometry, retina, POMT1, outer segments, KIAA1549, MDDG

\section{INTRODUCTION}

Muscular dystrophy-dystroglycanopathies (MDDGs) are a group of autosomal recessive disorders associated with defects in the glycosylation of $\alpha$-dystroglycan ( $\alpha$-DG), the central component of the dystrophin-glycoprotein complex (DGC). ${ }^{1,2}$ The DGC is responsible for physically linking the cytoskeleton and the extracellular matrix (ECM) in muscle and neural cells. ${ }^{3,4}$ MDDGs display a broad spectrum of neurological alterations, which extend in most cases to the retina. ${ }^{1}$ The $\alpha$-DG needs to be extensively glycosylated for its proper functioning, interacting through its $O$-mannosyl glycans with several proteins of the ECM, such as laminin, agrin, neurexin, perlecan, slit, and pikachurin, the latter exclusively in the retina. ${ }^{2,5,6}$ The process of $\alpha$-DG $O$-mannosylation begins in the endoplasmic reticulum, where a mannosyl residue is transferred from dolichyl phosphate mannose to Ser/Thr residues. This process is carried out by the heterocomplex formed by protein $O$-mannosyltransferases 1 (POMT1) and 2 (POMT2). ${ }^{7-9}$ Although $\alpha$-DG is the beststudied substrate of POMT1/2, there are indications of a few other substrates of this enzyme complex, but the role of $O$ mannosylation of these proteins is less understood. ${ }^{10}$

Mutations in the POMT1 gene cause three different forms of MDDGs, including the most severe type, involving brain and eye anomalies (MDDGA1) previously known as the WalkerWarburg syndrome (WWS) or muscle-eye-brain disease (MEB), ${ }^{1,12}$ in addition to other milder syndromes like MDDGB1 and MDDGC1. ${ }^{13,14}$ To date, a wide variety of ocular abnormalities have been described in patients with POMT1 mutations suffering from WWS or MEB, including retinal malformations (dysplasia, atrophy, and detachment), vitreoretinal dysgenesis, optic nerve hypoplasia, and blindness. ${ }^{12,15}$ These ocular symptoms in MDDGA1 patients have been mostly associated with the absence of glycosylation of $\alpha$-DG as a consequence of the functional loss of POMT1. However, the link between this enzyme and reported phenotypic changes is often not well understood.

Given that Pomt1 $1^{-/-}$mice experience early embryonic death, ${ }^{16}$ a Pomt 1 conditional knockout (Pomt1 cKO) mouse model was recently generated. ${ }^{17}$ This animal contains a deletion in the Pomt 1 gene specifically in the photoreceptor cells of the retina and showed an incorrect formation of synaptic complexes in the so-called outer plexiform layer (OPL). Consequently, the transmission of the visual signals from photoreceptors to their postsynaptic cells was severely affected. Overall, the conditional inactivation of Pomt1 in photoreceptors mimics to a large extent the visual defects seen in patients with WWS and other MDDGs associated with a mutation in the POMT1 gene. ${ }^{17}$ However, it is so far unclear whether this can be fully ascribed to $\alpha$-DG hypoglycosylation or whether other processes are also affected.

Received: February 12, 2021

Published: May 24, 2021 
In this work, we use mass spectrometry-based quantitative retinal proteomics combined with immunofluorescence techniques to gain a deeper understanding of the molecular and morphological changes in the retina of Pomt 1 cKO mice. Of note, in addition to effects associated with $\alpha$-DG hypoglycosylation, we show the downregulation of a relatively understudied POMT1 substrate, KIAA1549, and propose a role for this protein in the retinal changes that we observed in Pomt $1 \mathrm{cKO}$ mice.

\section{EXPERIMENTAL PROCEDURES}

\section{Mice}

The strategy used to generate Pomt1 conditional knockout (Pomt1 cKO) mice was published previously. ${ }^{17}$ In brief, the Cre/ loxP system was used for obtaining a mouse carrying homozygous Pomt 1 floxed alleles and the $\mathrm{Cr} x$-Cre transgene. ${ }^{18}$ In those animals the Cre recombinase activity was driven by the promoter of the cone-rod homeobox $(\mathrm{Cr} x)$ gene, encoding a transcription factor essential for the development of photoreceptors. All procedures were performed according to the Spanish and European legislation, and experiments were approved by the Ethics Committees of the Universidad Autónoma de Madrid.

\section{Hematoxylin and Eosin Staining}

Eyecups from Pomt $1 \mathrm{cKO}$ and control mice (4-6 months old) were fixed in $4 \%$ paraformaldehyde, cryoprotected with sucrose, and embedded in optimal cutting temperature compound (Miles Inc.). Tissues were frozen in liquid $\mathrm{N}_{2}$, and then 14-16 $\mu \mathrm{m}$ sections were obtained using a cryostat. Hematoxylin and eosin staining was carried out as described. ${ }^{19}$

\section{Immunofluorescence}

Retinal cryosections were obtained and processed essentially as described. $^{20,21}$ Briefly, retinal sections were blocked with 5\% BSA for $1 \mathrm{~h}$ and subjected to single immunostaining with antibodies against recoverin (Millipore, Cat\# AB5585), rhodopsin (Millipore, Cat\# MAB5356), CNGB1, ${ }^{22}$ C-arrestin (Millipore, Cat\# AB15282), GFAP (Sigma-Aldrich, Cat\# G3893), FGF2 (Millipore, Cat\# 05-118), and KIAA1549 (Sigma-Aldrich, Cat\# HPA019560) at room temperature overnight. Thereafter, the slides were incubated for $1 \mathrm{~h}$ at room temperature with secondary antibodies conjugated to Alexa Fluor 488 (Molecular Probes, Cat\# A-21206, and Cat\# A21202) or Alexa Fluor 555 (Molecular Probes, Cat\# A-31570, and Cat\# A-31572). 4',6-Diamidino-2-phenylindole (DAPI, Sigma-Aldrich) was simultaneously used for counterstaining. The negative control consisted of samples in which primary antibodies were omitted but were processed in parallel. Images of the slides were taken with a Leica TCS SP2 confocal laser scanning microscope (Leica Microsystems) and processed using ImageJ software.

Proteomics Sample Preparation and Dimethyl Isotope Labeling

Neural retinas (both eyes) of control and Pomt 1 cKO mice (6 months old) were dissected from the eyecups and stored at -20 ${ }^{\circ} \mathrm{C}$. Retinal tissues were homogenized in extraction buffer $(5 \%$ SDS, $100 \mathrm{mM}$ Tris/ $\mathrm{HCl} \mathrm{pH} \mathrm{7.6;} 150 \mu \mathrm{L}$ per $25 \mathrm{mg}$ of tissue), incubated at $95{ }^{\circ} \mathrm{C}$ for $4 \mathrm{~min}$, sonicated on ice (20\% output; 20 $\mathrm{s}$ ), and subjected to BCA protein assays. Dithiothreitol (DTT, $0.5 \mathrm{M}$ ) was then added to a final concentration of $100 \mathrm{mM}$ and proteins were reduced by incubating the samples at $95{ }^{\circ} \mathrm{C}$ for 4 min. From each sample, $150-200 \mu \mathrm{g}$ of total protein was transferred to a $30 \mathrm{kDa}$ filter unit (Millipore) and centrifuged at $14000 \mathrm{~g}$ for $30 \mathrm{~min}$. Then, $200 \mu \mathrm{L}$ of solution A ( $8 \mathrm{M}$ urea in 100 $\mathrm{mM}$ Tris- $\mathrm{HCl} \mathrm{pH} 8.5)$ was added to the filter and the samples were centrifuged again. Next, $100 \mu \mathrm{L}$ of fresh IAA solution ( 0.05 $\mathrm{M}$ iodoacetamide in solution $\mathrm{A}$ ) was added, mixed, and then incubated for $10 \mathrm{~min}$ at room temperature. After centrifugation at $14000 \mathrm{~g}$ for $30 \mathrm{~min}, 100 \mu \mathrm{L}$ of solution B ( $8 \mathrm{M}$ urea in $100 \mathrm{mM}$ Tris- $\mathrm{HCl} \mathrm{pH} \mathrm{8.0)} \mathrm{was} \mathrm{added} \mathrm{to} \mathrm{the} \mathrm{filter,} \mathrm{and} \mathrm{samples} \mathrm{were}$ centrifuged one more time. This step was repeated two times. Then, $40 \mu \mathrm{L}$ of solution B containing $10 \mu \mathrm{g}$ of endoLys-C was added to the filter. Following mixing at $600 \mathrm{rpm}$ for $1 \mathrm{~min}$, the samples were incubated in a wet chamber (a $50 \mathrm{~mL}$ tube containing a few drops of water) overnight at room temperature. The filters were then transferred to a new collection tube, and $120 \mu \mathrm{L}$ of $25 \mathrm{mM} \mathrm{NH}_{4} \mathrm{HCO}_{3}$ containing $10 \mu \mathrm{g}$ of trypsin was added, mixed thoroughly, incubated at room temperature for 4 $\mathrm{h}$, and centrifuged at $14000 \mathrm{~g}$ for $30 \mathrm{~min}$. Finally, $50 \mu \mathrm{L}$ of $0.5 \mathrm{M}$ $\mathrm{NaCl}$ was added to the filters to elute the peptides by centrifugation at $14000 \mathrm{~g}$ for $15 \mathrm{~min}$, in a clean collection tube. Subsequently, $40 \mu \mathrm{g}$ of peptides of each sample were desalted on a C18 Oasis (HLB, Waters Inc.) and subsequently derivatized on a column by dimethyl labeling using light $(+28$ $\mathrm{Da})$ and medium (+32 Da) labels, respectively. ${ }^{23}$ The samples were then combined and stored at $-80{ }^{\circ} \mathrm{C}$.

\section{Strong Cation Exchange Chromatography (SCX)}

For SCX separations, ${ }^{24}$ the derivatized peptides were fractionated using a homemade SCX column $(320 \mu \mathrm{m}$ inner diameter, $15 \mathrm{~cm}$, polysulfoethyl A $3 \mu \mathrm{m}$, Poly LC), run at $4 \mu \mathrm{L} / \mathrm{min}$. Gradients were run for $10 \mathrm{~min}$ at $100 \%$ solvent A (100\% water/ $0.1 \%$ TFA), after which a linear gradient started to reach $100 \%$ solvent B (250 mm KCl, 35\% ACN/0.1\% TFA) over $15 \mathrm{~min}$, followed by $100 \%$ solvent $\mathrm{C}(500 \mathrm{mM} \mathrm{KCl}, 35 \% \mathrm{ACN} / 0.1 \%$ TFA) over the next $15 \mathrm{~min}$. The gradient remained at $100 \%$ solvent $\mathrm{C}$ for $5 \mathrm{~min}$ and then switched again to $100 \%$ solvent $\mathrm{A}$. Fifteen $4-\mu \mathrm{L}$ fractions were collected in vials prefilled with 100 $\mu \mathrm{L}$ of $95 / 3 / 0.1$ water/ACN/FA v/v/v.

\section{NanoLC-MS/MS}

Each SCX fraction was analyzed via online C18-nano-HPLCMS with a system consisting of an Easy-nLC 1000 gradient HPLC (Thermo Scientific) and a Q-Exactive mass spectrometer (Thermo Scientific). Fractions were injected into a homemade precolumn ( $100 \mu \mathrm{m} \times 15 \mathrm{~mm}$; Reprosil-Pur C18-AQ $3 \mu \mathrm{m}$, Dr. Maisch), equilibrated with solvent A (100/0.1 water/formic acid (FA) v/v), and eluted using a homemade analytical nanoHPLC column $(15 \mathrm{~cm} \times 50 \mu \mathrm{m}$; Reprosil-Pur C18-AQ $3 \mathrm{um})$. The gradient was run from 0 to $30 \%$ solvent $\mathrm{B}(100 / 0.1$ acetonitrile/formic acid (FA) v/v) in $120 \mathrm{~min}$. The nano-HPLC column was drawn to a $\sim 5 \mu \mathrm{m}$ tip and acted as the electrospray needle of the MS source. The Q-Exactive mass spectrometer was operated in top10-mode. Parameters were as follows: a resolution of 70000 at an AGC target value of 3 million with a maximum fill time of $20 \mathrm{~ms}$ (full scan) and a resolution of 17500 at an AGC target value of 100000 with a maximum fill time of $60 \mathrm{~ms}$ for MS/MS (normalized collision energy (NCE) $27 \%$, dynamic exclusion $30 \mathrm{~s}$ ) at an intensity threshold of 17000 . The apex trigger was set to $1-5 \mathrm{~s}$ and allowed charges were $2-5$. Data Analysis

For peptide identification, MS/MS spectra were searched against the UniProt Mus musculus database (downloaded September 2017, 52015 entries) using Mascot Version 2.2.07 (Matrix Science) with the following settings: $10 \mathrm{ppm}$ and 20 
A

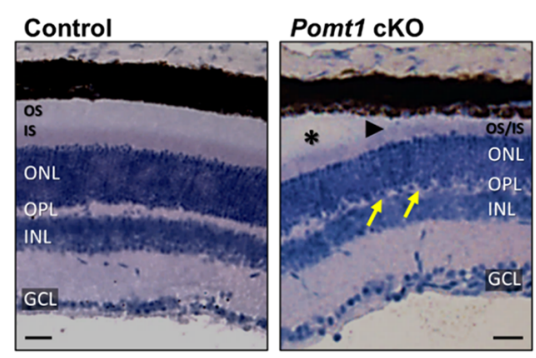

C

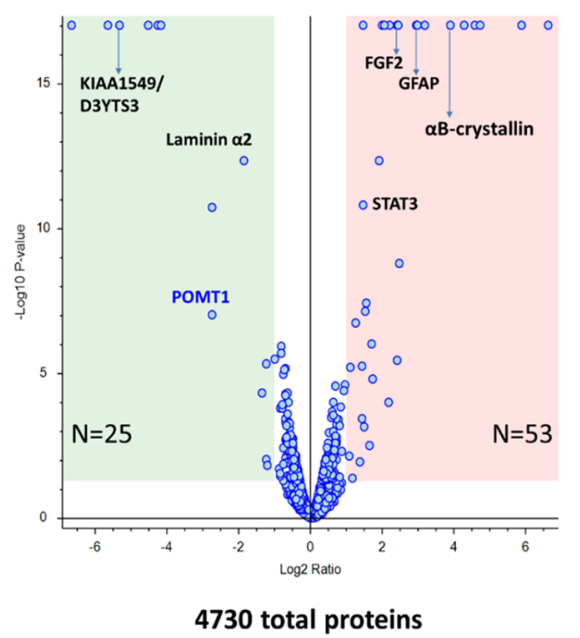

B

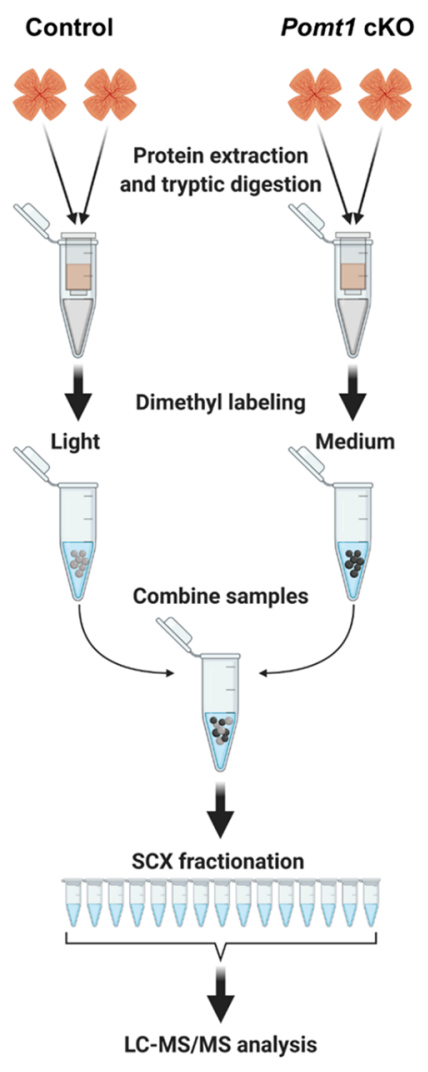

Figure 1. Histological and comparative proteomic analysis of Pomt $1 \mathrm{cKO}$ and control retinas. (A) Retinal sections of control and Pomt $1 \mathrm{cKO}$ mice were stained with hematoxylin-eosin. The Pomt $1 \mathrm{cKO}$ retinas showed a decreased in the thickness of the OS/IS sublayer of photoreceptors (arrowhead) and OPL (yellow arrows) and areas with detachment (asterisk). Scale bar: $20 \mu \mathrm{m}$. Abbreviations: OS, outer segments; IS, inner segments; ONL, outer nuclear layer; OPL, outer plexiform layer; INL, inner nuclear layer; GCL, ganglion cell layer. (B) Comparative proteomics analysis. Mouse retinas from control and Pomt $1 \mathrm{cKO}$ animals were dissected and proteins were extracted and digested with trypsin. Tryptic peptides were subjected to dimethyl labeling using either light (control) or medium (cKO) reagents. Control and cKO samples were then combined. Labeled peptides were fractionated using strong cation exchange (SCX) and fractions were subsequently analyzed by LC-MS/MS. Scheme in the figure was created with BioRender.com. (C) Volcano plot based on the core set of 4730 proteins that were identified in all three biological replicates and which showed consistent abundance ratios (see main text for details). Proteins at lower and higher levels $\left(\log _{2}\right.$ fold change lower or higher than 1 , BenjaminiHochberg adjusted $p$-value $<0.05)$ in the retina of Pomt $1 \mathrm{cKO}$ compared to control mice are shown in the left and right panel, respectively.

milli mass unit deviation for precursor and fragment masses, respectively; trypsin was set as the enzyme and one missed cleavage was allowed. Carbamidomethyl on cysteines was set as a fixed modification. Variable modifications were oxidation (on Met) and acetylation on the protein $\mathrm{N}$-terminus. In addition, light (dimethyl reductive amination) and medium (dimethyl reductive amination $\mathrm{d} 4$ ) dimethyl modifications on Lys and the peptide $\mathrm{N}$-terminus were set as variable modifications. All searches and subsequent data analysis, including Percolator ${ }^{25}$ and relative quantification, were performed using Proteome Discoverer 2.4 (Thermo Scientific). Peptide-spectrum matches were adjusted to a $1 \%$ FDR. STRING analysis was performed at https://string-db.org/. The mass spectrometry proteomics data have been deposited to the ProteomeXchange Consortium (http://proteomecentral.proteomexchange.org) via the PRIDE $^{26}$ partner repository with the dataset identifier PXD023704.

\section{Statistical Analyses}

Visualization and statistical analysis of data were performed using GraphPad Prism. Data are presented as mean \pm standard deviation (S.D.). Student's $t$-test was used to analyze the differences between groups. $* *=p<0.01, * * *=p<0.001$, $* * * *$ $=p<0.0001$.

\section{RESULTS}

\section{Differences in Protein Expression between Control and Pomt 1 cKO Retinas}

The Pomt 1 cKO mouse model analyzed in this work was generated and characterized as previously described. ${ }^{17}$ Here, we first performed hematoxylin-eosin staining of retinal crosssections of control and Pomt $1 \mathrm{cKO}$ mice. In addition to the previously described thinning of the outer nuclear layer (ONL) and OPL, a decrease in the thickness of the outer/inner segment (OS/IS) sublayer of photoreceptor cells in Pomt $1 \mathrm{cKO}$ mice was observed, with some detached regions (Figure 1A). Notwithstanding the importance of alterations in the DGC as a result of improper $\mathrm{O}$-mannosylation of $\alpha$-DG in Pomt $1 \mathrm{cKO}$ mice, we reasoned that additional effects might also contribute to the phenotypic changes observed in these mice. To address this at the molecular level, we performed comparative quantitative proteomics analyses on retinas from control and Pomt $1 \mathrm{cKO}$ mice in triplicate (Figure 1B).

Overall, our proteomics experiments led to the identification of 7471 mouse proteins (Table S1 and Figure S1). In the three biological replicates, a comparable normal distribution of $\log _{2}$ transformed abundance ratios was observed (Figure S1). 
However, we noticed that among all proteins that we identified many were either not observed in all three biological replicates or were present in inconsistent ratios (i.e., upregulated $\left(\log _{2}\right.$ fold change $>1)$ in one replicate, and downregulated $\left(\log _{2}\right.$ fold change $<-1)$ in another). For example, this was observed for the major lens crystallin proteins, i.e., $\beta$-A2, $\beta$-A4, $\beta$-B2, $\beta$-B3, $\beta \mathrm{S}$, and $\gamma \mathrm{D}$ crystallins (Figure S2). This is most probably the result of variable contamination with lens material during the preparation of the retina samples. On the other hand, $\alpha \mathrm{B}$ crystallin, which is found in other regions of the eye, ${ }^{27}$ showed consistently higher levels in the retina of Pomt 1 cKO (Figure S2). Based on these observations, we decided to focus our further analyses on proteins that were first of all found in all three biological replicates and showed consistent ratios. Hence, from the overall set of proteins (Figure S1), we selected only those proteins that either had an abundance ratio (Pomt1 cKO/ control) above 2, below 0.5 , or between 0.5 and 2 in all three biological replicates. In addition, to exclude proteins that were identified at relatively lower confidence, we limited ourselves to proteins that had a Mascot protein score above 50. Overall, this resulted in a core protein list of 4730 proteins (Table S2). The volcano plot based on these proteins ( $\log _{2}$ fold change $<-1$ or $>1$, Benjamini-Hochberg adjusted $p$-value $<0.05)$ showed that 25 proteins were found in lower levels and 53 proteins in higher levels in the retina from Pomt $1 \mathrm{cKO}$ mice (Figure 1C, and Tables S3 and S4).

As expected, POMT1 was among the proteins that were observed at reduced levels in Pomt 1 cKO mice (Figure 1C, Pomt $1 \mathrm{cKO} /$ control abundance ratio $0.12 \pm 0.09$, mean $\pm \mathrm{SD}$; $n$ $=3,1$ unique peptide). STRING analysis of all proteins that were found in lower levels in Pomt 1 cKO mice (Figure S3A) showed a link between POMT1 and laminin $\alpha-2$ (Pomt1 cKO/ control abundance ratio $0.27 \pm 0.17$, mean $\pm \mathrm{SD} ; n=3,22$ unique peptides) and between POMT1 and KIAA1549/ D3YTS3 (Pomt1 cKO/control abundance ratio $0.11 \pm 0.15$, mean $\pm \mathrm{SD} ; n=3,11$ unique peptides).

\section{Shortened Outer (OS) and Inner Segments (IS) of Pomt1} cKO Photoreceptors Are Associated with Lower Levels of OS Proteins

As mentioned above, the thickness of the OS/IS sublayer appeared to decrease in the retina of Pomt $1 \mathrm{cKO}$ mice. To corroborate this finding, we performed immunofluorescence staining of recoverin, a protein that is expressed in photoreceptor cells, and measured the width of the outer and inner segments in retinal sections. This analysis showed that the OS/ IS thickness was approximately $30 \%$ smaller in Pomt $1 \mathrm{cKO}$ mice (Figure 2A). In our analysis described above, we considered only $\log _{2}$ fold changes lower than -1 or higher than 1 (Figure 1C). However, a close inspection of our data revealed that the level of the major photoreceptors outer segment protein, rhodopsin, was also approximately $30 \%$ lower in the samples from Pomt $1 \mathrm{cKO}$ mice (Pomt $1 \mathrm{cKO} /$ control abundance ratio $0.72 \pm 0.11$, mean \pm SD; $n=3,9$ unique peptides, Table S2). This prompted us to perform STRING analysis using the proteins present in our core proteomics dataset exhibiting an average Pomt $1 \mathrm{cKO} / \mathrm{control}$ abundance ratio $<0.8$ (229 proteins in total). Indeed, this analysis yielded a cluster of 17 outer segment proteins (Figures 2B and S3B, blue circle) with a Pomt $1 \mathrm{cKO} /$ control abundance ratio of approx. 0.7. For several of these proteins, i.e., rhodopsin, CNGB1, and C-arrestin, the lower levels in the retina of Pomt1 cKO mice were confirmed by immunofluorescence microscopy (Figure 2C).
A
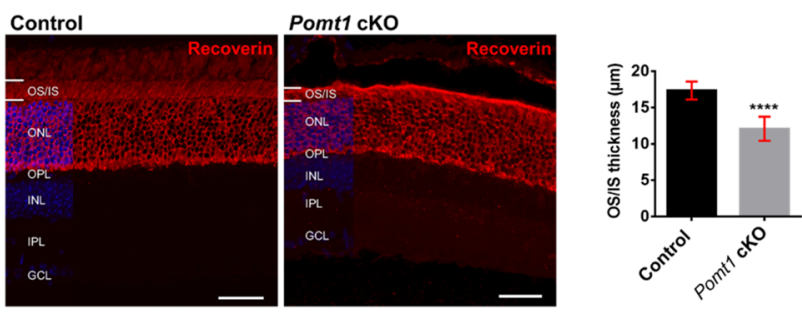

B
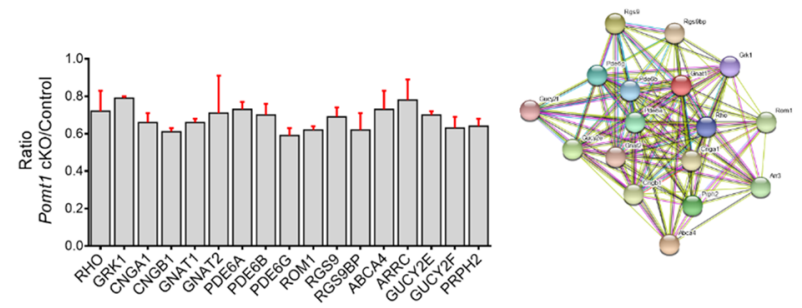

C

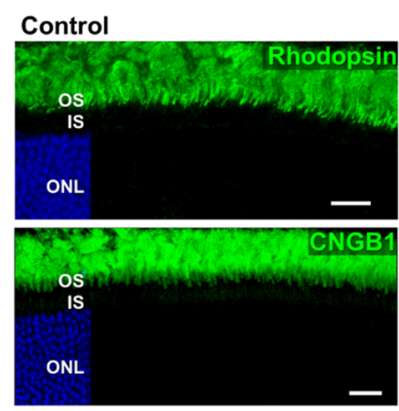

Pomt1 cKO
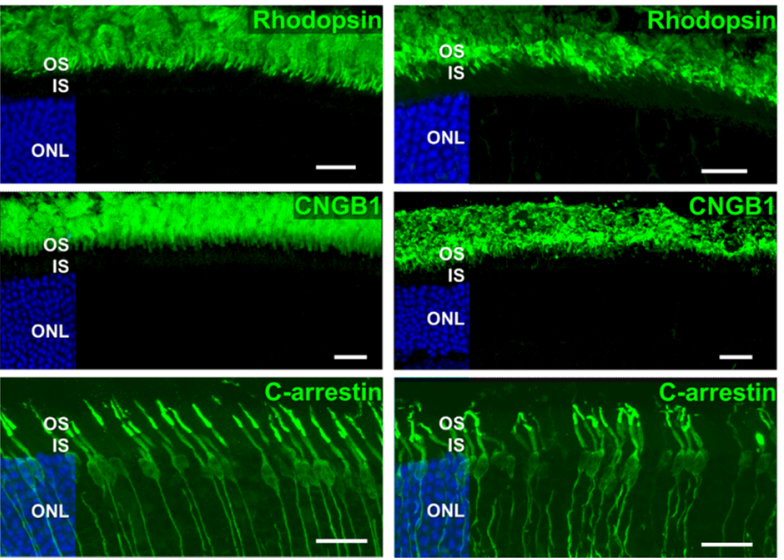

Figure 2. Shortened outer and inner segments of the Pomt1 cKO photoreceptors are associated with lower levels of phototransduction proteins. (A) Control and Pomt $1 \mathrm{cKO}$ retinal sections were labeled with an anti-recoverin antibody (red) and a nuclear dye, DAPI (blue). The length of the outer and inner segment sublayer of photoreceptors was measured in 10 photographs of each animal $(n=6)$. The bars correspond to the average, and the S.D. value is shown in red. Student's $t$-test: $* * * * p<0.0001$. (B) Pomt1 cKO/control abundance ratios (mean \pm S.D., $n=3$ ) of a cluster of major outer segment proteins. RHO $=$ Rhodopsin. For further details about this protein set, see Table S2. (C) Retinal sections of control and Pomt $1 \mathrm{cKO}$ mice were labeled with antibodies against the indicated proteins (green). DAPI was used as a counterstain. Abbreviations: OS, outer segments; IS, inner segments; ONL, outer nuclear layer; OPL, outer plexiform layer; INL, inner nuclear layer; IPL, inner plexiform layer; GCL, ganglion cell layer. Scale bars: A, $40 \mu \mathrm{m}$; C, $20 \mu \mathrm{m}$.

Interestingly, the STRING analysis (Figure S3B, green circle) also revealed a cluster of seven Bardet-Biedl Syndrome proteins (BBS 1, 2, 4, 5, 7, 8, and 9), which together form the base of the cilium connecting the inner and outer segments of the photoreceptors and are collectively called BBSome (Figure $3 \mathrm{~A}){ }^{28}$ Also, for these proteins, consistent and highly reproducible lower levels were found in the retina of Pomt 1 cKO mice (Figure 3B, and Table S2). 
A

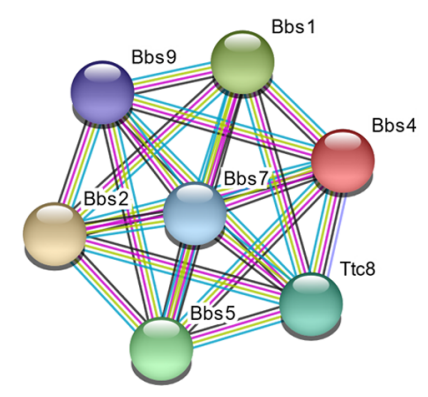

B

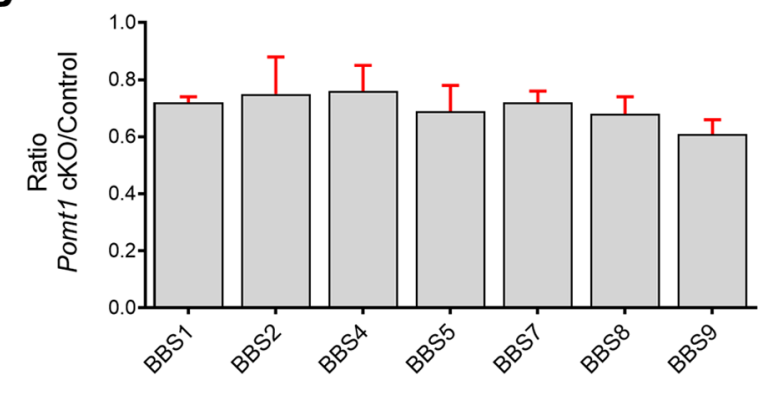

Figure 3. Reduced levels of Bardet-Biedl Syndrome (BBS) related proteins in the retina of Pomt1 cKO mice. (A) Cluster of BBS proteins (also see Figure S4) found after STRING analysis of proteins with Pomt $1 \mathrm{cKO} /$ control ratio $<0.8$. (B) Their respective abundance ratios are presented as means $( \pm$ S.D.) from three biological replicates (see Table S2 for more details).

A

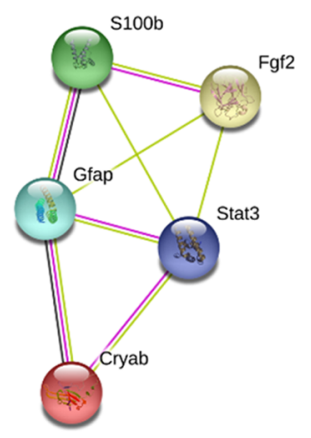

B

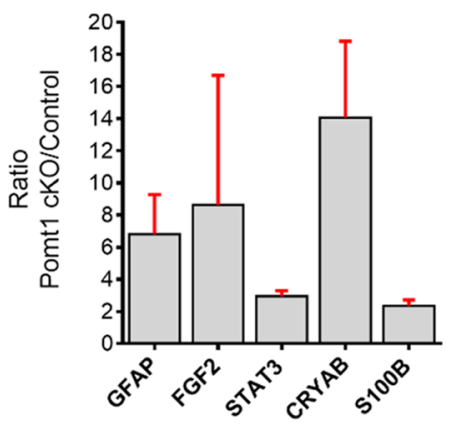

\section{C}

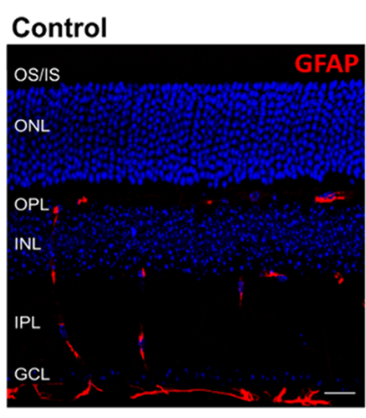

Pomt1 cKO
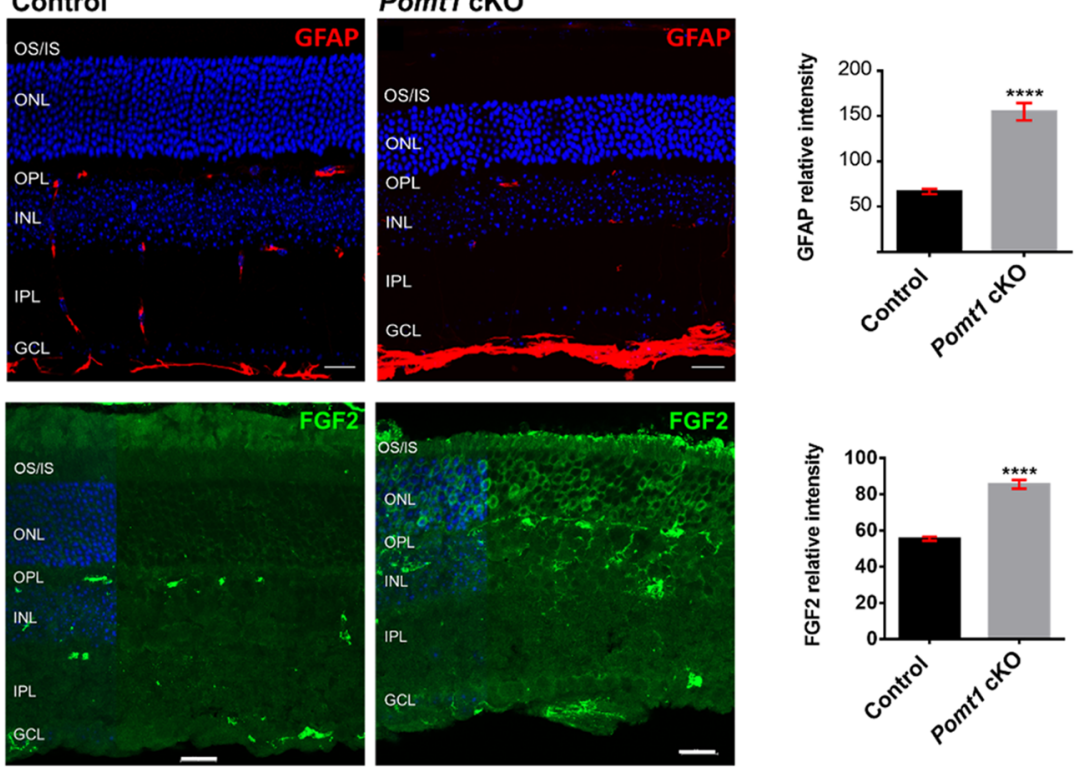

Figure 4. Upregulation of GFAP-associated proteins in the retina of Pomt $1 \mathrm{cKO}$ mice. (A) STRING analysis of proteins that were found in higher levels in the retina of Pomt $1 \mathrm{cKO}$ mice (Pomt $1 \mathrm{cKO} / \mathrm{control}>2$ ) (from Figure S4, blue circle) (B) Pomt $1 \mathrm{cKO} / \mathrm{control}$ abundance ratios (mean \pm S.D., $n=3$ ) of proteins of the GFAP-associated cluster in panel A. (C) Retinal sections of control and Pomt 1 cKO mice were labeled with anti-GFAP (red) or anti-FGF2 antibodies (green). Nuclei were stained with DAPI. The relative fluorescence intensity of GFAP and FGF2 was measured and is presented (mean \pm S.D.) in the right part of the panel. Student's $t$-test: $* * * * p<0.0001$. Abbreviations: OS, outer segments; IS, inner segments; ONL, outer nuclear layer; OPL, outer plexiform layer; INL, inner nuclear layer; IPL, inner plexiform layer; GCL, ganglion cell layer. Scale bars: $20 \mu \mathrm{m}$.

GFAP-Associated Proteins Are Upregulated in the Pomt1-Deficient Retina

Among the proteins that were upregulated in the retina of Pomt 1 cKO mice, we noticed in our STRING analysis a cluster of proteins around the glial fibrillary acidic protein (GFAP, Figure S4, blue circle; and Figure 4A), including FGF2, STAT3, and the aforementioned $\alpha \mathrm{B}$-crystallin (Figure 4B). Using immunofluorescence techniques, we found that the higher level of GFAP in Pomt $1 \mathrm{cKO}$ mice was restricted to the ganglion cell layer (Figure 

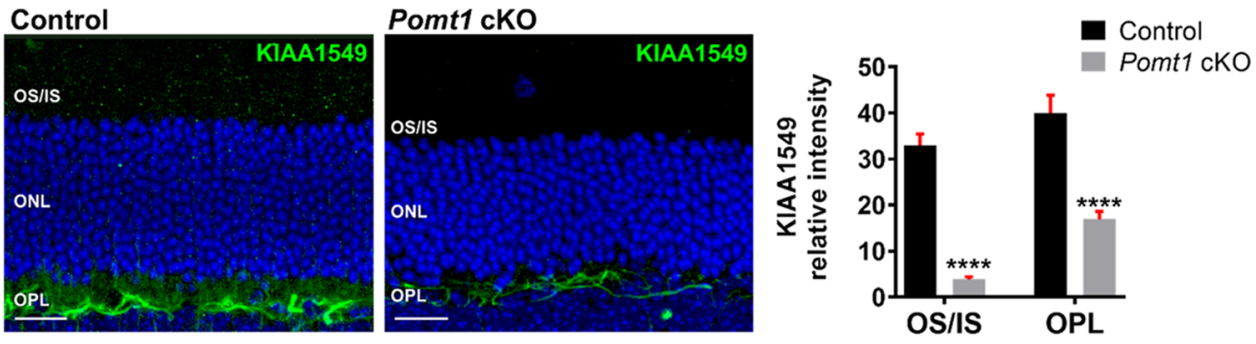

Figure 5. The POMT1 substrate KIAA1549 is downregulated in Pomt $1 \mathrm{cKO}$ retinas. Retinal sections of control and Pomt $1 \mathrm{cKO}$ mice were labeled with anti-KIAA1549 antibody (green) and DAPI. The relative fluorescence intensity of KIAA1549 at the OS/IS and OPL (mean \pm S.E.M., $n=15$ ) is presented in the right panel. Student's $t$-test: $* * * * p<0.0001$. Abbreviations: OS, outer segments; IS, inner segments; ONL, outer nuclear layer; OPL, outer plexiform layer. Scale bars: $20 \mu \mathrm{m}$.

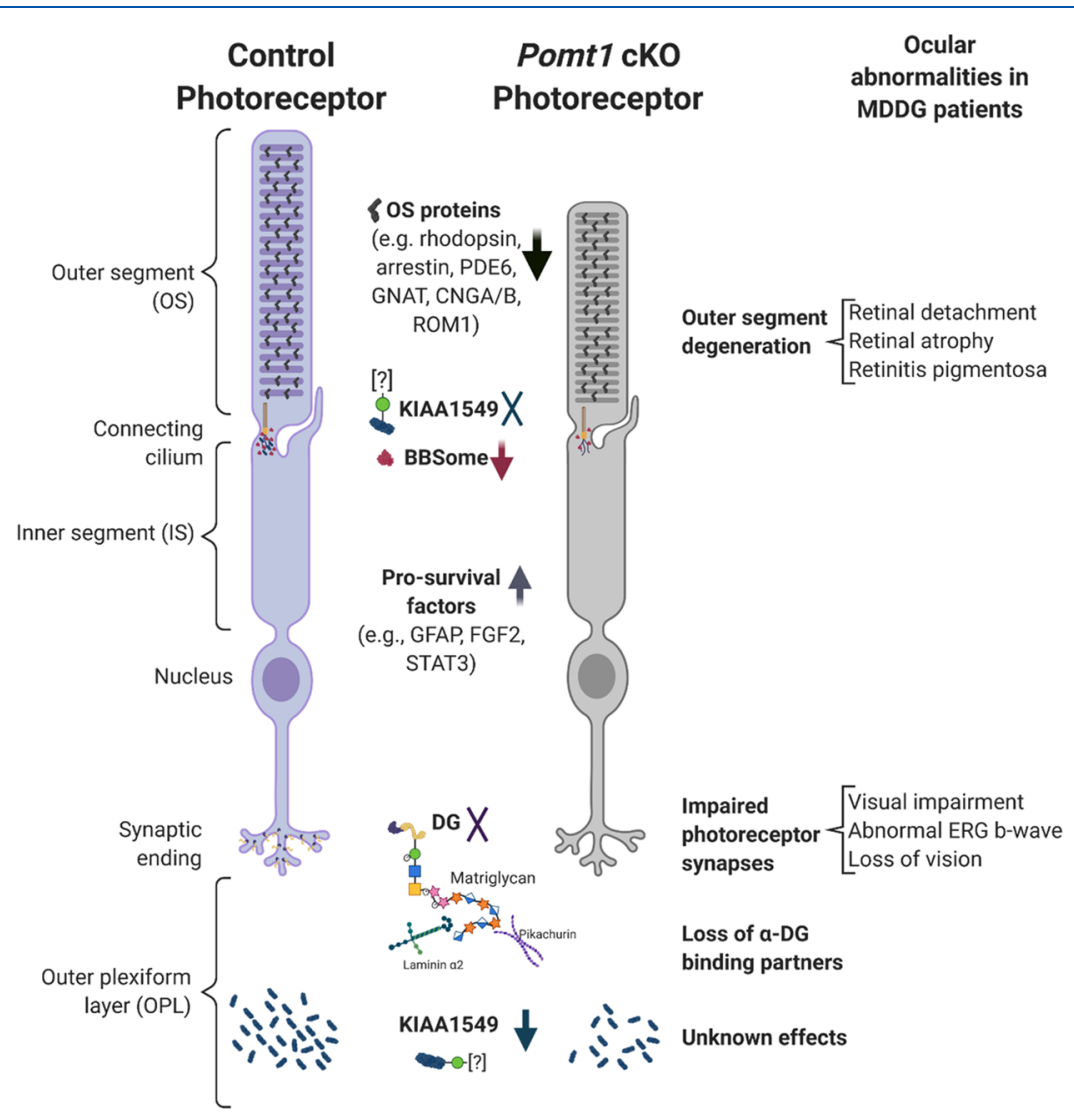

Figure 6. Model presenting the link between the proteomic and phenotypic changes observed in the retina of Pomt1 cKO mice, and ocular abnormalities seen in patients with MDDGs. In control photoreceptors, dystroglycan (DG) and KIAA1549 are both located in the outer plexiform layer (OPL). In addition, KIAA1549 is also located at the cilium connecting the outer and inner segments of photoreceptors. Under normal conditions, $O$-mannosylated (matriglycan) DG interacts at the synaptic cleft of photoreceptors with ECM proteins but in the Pomt cKO mice this interaction is impaired. ${ }^{17}$ The role of KIAA1549 and its O-Man glycans (either elongated or not, as indicated with [?]) at the synaptic ending are currently unknown. We propose that the loss of KIAA1549 at the connecting cilium in Pomt $1 \mathrm{cKO}$ mice results in the observed OS/IS shortening with a concomitant decrease of BBSome and outer segment (OS) proteins and an increase in the production of pro-survival factors. Patients with MDDGs exhibit ocular and visual impairments, e.g., retinal detachment, atrophy, retinitis pigmentosa, electroretinogram (ERG) abnormalities, and even vision loss, that could be related to the alterations seen in Pomt $1 \mathrm{cKO}$ mice. The figure was created using BioRender (https://biorender.com/).

4C). Given the fact that FGF2 is a known stress-induced protein

that becomes upregulated together with GFAP during retinal degeneration and optic nerve injury, ${ }^{29-31}$ we also analyzed

FGF2 levels by immunofluorescence. Our results showed increased levels of FGF2 mostly in the photoreceptor cell bodies of Pomt1 cKO retinas (Figure 4C).
POMT1 Substrate KIAA1549 Is Downregulated in the Outer Plexiform Layer and Inner/Outer Segments of Photoreceptor Cells from Pomt 1 cKO Mice

Given its great involvement in the pathogenesis of dystroglycanopathies, the hitherto best-studied POMT1 substrate is $\alpha$ DG. From our proteomics data, no effects on the overall levels of DG (Pomt $1 \mathrm{cKO} /$ control abundance ratio $1.12 \pm 0.1$, mean \pm $\mathrm{SD} ; n=3,13$ unique peptides) in our retina samples were observed (Table S2). Currently, only a very limited number of as yet unexplored POMT1 substrates have been described. ${ }^{32}$ One 
of these is KIAA1549 (Uniprot ID: D3YTS3), which was found in lower levels in the retina of Pomt $1 \mathrm{cKO}$ mice (Figure 1C). Recently the location of this protein was shown at the connecting cilium of photoreceptor cells and in the OPL of the mouse retina. ${ }^{33}$ Indeed, using immunofluorescence staining, KIAA1549 was observed mainly in the OPL, and also in the OS/ IS of photoreceptors in retinal sections of control mice (Figure 5 ). In line with our proteomics data, highly reduced levels of KIAA1549 were detected in the retinal OPL of Pomt $1 \mathrm{cKO}$ mice. Moreover, KIAA1549 was almost absent in the photoreceptor layer in these mice.

\section{DISCUSSION}

The importance of $\alpha$-DG and its $O$-mannosylation has been well documented in different mouse models, either by deleting $\alpha$-DG itself $^{34}$ or the genes responsible for the synthesis of its $O$ mannosyl glycans. ${ }^{16,35-37}$ Some of these models have made it possible to study the systemic effect of loss-of-function mutations, mimicking the characteristic symptoms of patients with muscular dystrophy-dystroglycanopathies (MDDGs). However, due to the embryonic lethality of several constitutive gene-deletion mutations, ${ }^{38-40}$ other models used conditional knockouts. Here, we have further characterized a conditional knockout mouse model (Pomt1 cKO) harboring a Pomt 1 intragenic deletion selectively in photoreceptor cells, which previously showed improper formation of synaptic complexes at the OPL, and impaired transmission of visual signals between photoreceptors and their postsynaptic cells. ${ }^{17}$ Using comparative mass spectrometry-based proteomics and immunofluorescence microscopy, we here provide evidence that in addition to alterations associated with incorrect $\alpha$-DG $O$-mannosylation, other retinal processes are also affected.

As expected, a marked reduction in POMT1 levels was observed in Pomt 1 cKO retinas, accompanied by a decrease in one of the ECM $\alpha$-DG-interacting proteins, laminin $\alpha 2$. The fact that the quantification of POMT1 was based only on a single peptide probably reflects the low abundance of the enzyme, as we also experienced in our previous assays by Western blotting, ${ }^{21}$ and by immunofluorescence to validate the knockout model. ${ }^{17}$ Our proteomics data also highlight how even small differences in protein abundance can be of biological significance, as exemplified by the changes observed in the outer segment (OS) proteins and the BBSome protein complex. The high average number of peptides per protein that could be used for their quantification allowed for a high precision with which the difference could be determined. In fact, our analysis of slightly lower levels of proteins (Pomt $1 \mathrm{cKO} /$ control < 0.8$)$ not only revealed additional proteins in the network of $\alpha$-DGinteracting proteins, such as agrin and perlecan, but also a member of the specific dystroglycan-pikachurin complex in the retina, namely GPR $179 .{ }^{41}$ Pikachurin itself was identified only in two of the biological replicates, and although very lower levels were identified in the Pomt 1 cKO retina, it was not part of our further analyses due to our stringent filtering conditions. Overall, the observed proteomic changes reinforce the importance of $\alpha$ DG glycosylation for the proper expression and localization of several ECM components in the retina (Figure 6), as it had been shown in different mouse models of dystroglycanopathies. ${ }^{17,39,41}$

Mass spectrometry-based glycoproteomics strategies of several cellular model systems have been used to investigate the extent of protein $O$-mannosylation. ${ }^{42-44}$ In fact, one such study formed the basis for a paradigm shift by showing that $O$ - mannosylation can occur independently of POMT1 and 2 activity. ${ }^{32}$ This other $O$-mannosylation process results in nonelongated, single $O$-mannose ( $O$-Man) glycans, targeting the family of cadherins and plexins and involving an alternative set of proteins with putative glycosyltransferase activity. ${ }^{45}$ In accordance with this, we did not observe differences in the levels of cadherins and plexins in the retina of Pomt $1 \mathrm{cKO}$ mice. On the other hand, the abovementioned study clearly showed that $O$ mannosylation of KIAA1549 is dependent on POMT1/2. In total, 64 O-Man sites were identified on human KIAA1549, ${ }^{43}$ even though it is hitherto unknown whether its $O$-Man glycans are further elongated to form larger structures such as matriglycan. ${ }^{32}$ At present, no information on $\mathrm{O}$-Man glycosites in mouse KIAA1549 is available. Nevertheless, the downregulation of KIAA1549 in the mouse retina of the Pomt $1 \mathrm{cKO}$ mice evidenced here, strongly suggests that $O$-mannosylation is important for its proper transportation and/or stability. Our data also indicate that selective expression of KIAA1549 occurs in photoreceptor cells of the retina and suggest a possible role of this protein in the formation and functioning of the synapse between photoreceptors and their postsynaptic cells (Figure 6), due to the staining that we and others ${ }^{33}$ observed in the synaptic space, but this warrants further studies.

Of note, homozygous mutations in the KIAA1549 gene cause retinitis pigmentosa-86 (RP86, MIM: \# 618613), which courses with clinical symptoms including atrophy of the outer retinal layers with preservation of the photoreceptors in the fovea, and degenerated photoreceptor outer segments. ${ }^{33}$ Therefore, here we hypothesize that the shortening of the OS/IS segments of the photoreceptors observed in the retina of Pomt $1 \mathrm{cKO}$ mice is not directly related to $\alpha$-DG glycosylation, but occurs due to the loss of KIAA1549 (Figure 6) at the cilium, with a concomitant change in the BBSome complex as described above. There are currently no data available on the function of KIAA1549, other than that fusion with the kinase BRAF, which, as observed in pilocytic astrocytoma, results in constitutive kinase activity. ${ }^{46}$ Hence, further studies on the role of KIAA1549 and its $O$ mannosylation in the photoreceptor cilium are needed to test our hypothesis.

Interestingly, we found the upregulation of a set of proteins that are commonly expressed in degenerating neurons prior to cell death. This cluster includes glial fibrillary acidic protein (GFAP), basic fibroblast growth factor (FGF2), signal transducer, and activator of transcription 3 (STAT3), $\alpha \mathrm{B}$-crystallin (CRYAB), and S100 calcium binding protein B (S100B). The upregulation of both GFAP (a stress marker) and FGF2 (a prosurvival factor) has been reported to occur during the early stages of development of retinopathies in animal models, ${ }^{30,47-49}$ and has been associated with neuro- and retina-protective roles and maintenance of photoreceptor morphological integrity. Moreover, the upregulation and activation of STAT3 have also been implicated in protecting photoreceptors by regulating the expression of pro-survival molecules like FGF2. ${ }^{50,51}$ The function of $\alpha \mathrm{B}$-crystallin in healthy as well as diseased retinas has been widely studied. ${ }^{27}$ Its regulation has been implicated in numerous pathways such as inflammation, inhibition of apoptosis, angiogenesis, and also protection of photoreceptors. Overall, we believe that the upregulation of the above set of proteins represents a protective mechanism against photoreceptor degeneration in Pomt $1 \mathrm{cKO}$ mice.

Although our results contribute to a better understanding of the relationship between retinal symptoms experienced by patients with MDDGA1 and the loss of $O$-mannosylation, ocular 
symptoms that involve compartments other than the retina, such as congenital cataract, hyperplastic primary vitreous, optic nerve hypoplasia, congenital glaucoma, and corneal opacity ${ }^{1,12}$ would require broader analyses. Nonetheless, our proteomics data (Tables S3 and S4) provide some affected proteins in the retina of Pomt $1 \mathrm{cKO}$ mice that have previously been shown to be associated with several related clinical syndromes e.g., versican in Wagner vitreoretinopathy (MIM: \# 143200), $\alpha$-galactosidase A in Fabry disease (MIM: \# 301500), and the aforementioned $C R Y A B$ gene that appear mutated in multiple cataract types (MIM: \# 613763).

In summary, using quantitative mass spectrometry-based proteomics, the present study provides insight into the effect of aberrant $\mathrm{O}$-mannosylation due to the loss of POMT 1 activity in photoreceptor cells. Even though most of the phenotypic changes in MDDGs involving POMT1 mutations have thus far primarily been explained by the loss of $\alpha$-DG glycosylation, our study provides evidence that other processes are affected as well. This suggests that part of the clinical spectrum, such as retinal degeneration, detachment, and atrophy, could be caused by the dysregulation of other photoreceptor proteins such as the POMT1 substrate KIAA1549.

\section{ASSOCIATED CONTENT}

\section{SI Supporting Information}

The Supporting Information is available free of charge at https://pubs.acs.org/doi/10.1021/acs.jproteome.1c00126.

Overall results from comparative mass spectrometrybased quantitative proteomics of control and Pomt $1 \mathrm{cKO}$ mice (Figure S1); abundance ratios for different crystallins in the three different biological replicates (Figure S2); STRING analyses of proteins found in lower levels in the retina of Pomt1 cKO mice in the core set of 4730 proteins (Figure S3); STRING analysis of proteins found in higher levels in the retina of Pomt $1 \mathrm{cKO}$ mice in the core set of 4730 proteins (Figure S4) (PDF)

Overall set of 7471 proteins identified by mass spectrometry-based retinal proteomics of control and Pomt1 cKO mice (Table S1) (XLSX)

Core set of 4730 proteins identified by mass spectrometry-based retinal proteomics of control and Pomt1 cKO mice (Table S2) (XLSX)

Downregulated proteins in the core set of 4730 proteins (Table S3) (XLSX)

Upregulated proteins in the core set of 4730 proteins (Table S4) (XLSX)

\section{AUTHOR INFORMATION}

\section{Corresponding Authors}

Mary Luz Uribe - Center for Proteomics and Metabolomics, Leiden University Medical Center, 2333 ZA Leiden, The Netherlands; Departamento de Fisiología, Genética y Microbiología, Universidad de Alicante, 03080 Alicante, Spain; Present Address: Department of Biological Regulation, Weizmann Institute of Science, 76100 Rehovot, Israel.; 이 orcid.org/0000-0002-6567-2436; Email: mary.uribe@ua.es

Paul J. Hensbergen - Center for Proteomics and Metabolomics, Leiden University Medical Center, 2333 ZA Leiden, The Netherlands; 10 orcid.org/0000-0002-3193-5445; Email: P.J.Hensbergen@lumc.nl

\section{Authors}

José Martín-Nieto - Departamento de Fisiología, Genética y Microbiología, Universidad de Alicante, 03080 Alicante, Spain; Instituto Multidisciplinar para el Estudio del Medio "Ramón Margalef", Universidad de Alicante, 03080 Alicante, Spain

Cristina Quereda - Departamento de Fisiología, Genética y Microbiología, Universidad de Alicante, 03080 Alicante, Spain

Marcos Rubio-Fernández - Instituto Multidisciplinar para el Estudio del Medio "Ramón Margalef", Universidad de Alicante, 03080 Alicante, Spain; Present

Address: Neurodegenerative Disorders Group, Instituto de Investigación Hospital 12 de Octubre $(\mathrm{i}+12)$ and Network Center for Biomedical Research in Neurodegenerative Diseases, CIBERNED, 28041 Madrid, Spain.

Jesús Cruces - Departamento de Bioquímica, Instituto de Investigaciones Biomédicas "Alberto Sols" UAM-CSIC, Universidad Autónoma de Madrid, 28029 Madrid, Spain

George M. C. Janssen - Center for Proteomics and Metabolomics, Leiden University Medical Center, 2333 ZA Leiden, The Netherlands

Arnoud H. de Ru - Center for Proteomics and Metabolomics, Leiden University Medical Center, 2333 ZA Leiden, The Netherlands

Peter A. van Veelen - Center for Proteomics and Metabolomics, Leiden University Medical Center, 2333 ZA Leiden, The Netherlands; 10 orcid.org/0000-0002-7898-9408

Complete contact information is available at: https://pubs.acs.org/10.1021/acs.jproteome.1c00126

\section{Author Contributions}

M.L.U., J.M.-N., and P.J.H. designed the study. M.R.-F. and J.C. provided the biological material. G.M.C.J., A.H.d.R., P.A.v.V., and P.J.H. performed proteomics analyses and analyzed MS data. M.L.U. and C.Q. performed sample preparation and microscopy analyses. M.L.U. and J.M.-N. interpreted microscopy data. M.L.U. and P.J.H. analyzed and interpreted overall data and wrote the manuscript. J.M.-N., M.R.-F., J.C., G.M.C.J., A.H.d.R., and P.A.v.V. reviewed the manuscript.

\section{Notes}

The authors declare no competing financial interest.

The mass spectrometry proteomics data have been deposited to the ProteomeXchange Consortium Archive (http:// proteomecentral.proteomexchange.org) via the PRIDE partner repository with the dataset identifier PXD023704

\section{ACKNOWLEDGMENTS}

We thank the European Conditional Mouse Mutagenesis (EUCOMM) project for generating and providing the Pomt1 targeted ES cells, and Dr. Stylianos Michalakis (LudwigMaximilians-Universität München) for his generous gift of CNGB1 antibody. Our studies were supported, in part, by the Institute of Health Carlos III grants PI12/0157 and PI15/073 (to J.C. and J.M.-N.), and by the Comunidad de Madrid ("VISIONANIMAL" Biomedicine project S2010/BMD2439 to J.C.) all of them co-financed by the European Regional Development Fund (ERDF/FEDER). Additional research funding was provided by the Universidad de Alicante through grants for use of technical/research facilities (UAUSTI19-17 to J.M.-N.), scientific productivity (VIGROB-237 to J.M.-N.), and a short stay abroad (UAEEBB2015FPU-14 to M.L.U.). 


\section{REFERENCES}

(1) Godfrey, C.; Foley, A. R.; Clement, E.; Muntoni, F. Dystroglycanopathies: Coming into Focus. Curr. Opin. Genet. Dev. 2011, 21, 278-285.

(2) Endo, T. Glycobiology of -Dystroglycan and Muscular Dystrophy. J. Biochem. 2015, 157, 1-12.

(3) Barresi, R.; Campbell, K. P. Dystroglycan: From Biosynthesis to Pathogenesis of Human Disease. J. Cell Sci. 2006, 119, 199-207.

(4) Muntoni, F.; Brockington, M.; Torelli, S.; Brown, S. C. Defective Glycosylation in Congenital Muscular Dystrophies. Curr. Opin. Neurol. 2004, 17, 205-209.

(5) Bouchet-Séraphin, C.; Vuillaumier-Barrot, S.; Seta, N. Dystroglycanopathies: About Numerous Genes Involved in Glycosylation of One Single Glycoprotein. J. Neuromuscular Dis. 2015, 2, 27-38.

(6) Sato, S.; Omori, Y.; Katoh, K.; Kondo, M.; Kanagawa, M.; Miyata, K.; Funabiki, K.; Koyasu, T.; Kajimura, N.; Miyoshi, T.; Sawai, H.; Kobayashi, K.; Tani, A.; Toda, T.; Usukura, J.; Tano, Y.; Fujikado, T.; Furukawa, T. Pikachurin, a Dystroglycan Ligand, Is Essential for Photoreceptor Ribbon Synapse Formation. Nat. Neurosci. 2008, 11, 923-931.

(7) Manya, H.; Chiba, A.; Yoshida, A.; Wang, X.; Chiba, Y.; Jigami, Y.; Margolis, R. U.; Endo, T. Demonstration of Mammalian Protein OMannosyltransferase Activity: Coexpression of POMT1 and POMT2 Required for Enzymatic Activity. Proc. Natl. Acad. Sci. U.S.A. 2004, 101, $500-505$.

(8) Akasaka-Manya, K.; Manya, H.; Hayashi, M.; Endo, T. Different Roles of the Two Components of Human Protein O-Mannosyltransferase, POMT1 and POMT2. Biochem. Biophys. Res. Commun. 2011, 411, 721-725.

(9) Lommel, M.; Willer, T.; Cruces, J.; Strahl, S. POMT1 Is Essential for Protein O-Mannosylation in Mammals. Methods Enzymol. 2010, 479, 323-342.

(10) Dwyer, C. A.; Baker, E.; Hu, H.; Matthews, R. T. RPTP $\zeta /$ Phosphacan Is Abnormally Glycosylated in a Model of Muscle-EyeBrain Disease Lacking Functional POMGnT1. Neuroscience 2012, 220, 47-61.

(11) Beltrán-Valero de Bernabé, D.; Currier, S.; Steinbrecher, A.; Celli, J.; van Beusekom, E.; van der Zwaag, B.; Kayserili, H.; Merlini, L.; Chitayat, D.; Dobyns, W. B.; Cormand, B.; Lehesjoki, A.-E.; Cruces, J.; Voit, T.; Walsh, Ca.; van Bokhoven, H.; Brunner, H. G. Mutations in the O-Mannosyltransferase Gene POMT1 Give Rise to the Severe Neuronal Migration Disorder Walker-Warburg Syndrome. Am. J. Hum. Genet. 2002, 71, 1033-1043.

(12) Godfrey, C.; Clement, E.; Mein, R.; Brockington, M.; Smith, J.; Talim, B.; Straub, V.; Robb, S.; Quinlivan, R.; Feng, L.; JimenezMallebrera, C.; Mercuri, E.; Manzur, A. Y.; Kinali, M.; Torelli, S.; Brown, S. C.; Sewry, C. A.; Bushby, K.; Topaloglu, H.; North, K.; Abbs, S.; Muntoni, F. Refining Genotype-Phenotype Correlations in Muscular Dystrophies with Defective Glycosylation of Dystroglycan. Brain 2007, 130, 2725-2735.

(13) van Reeuwijk, J.; Maugenre, S.; van den Elzen, C.; Verrips, A.; Bertini, E.; Muntoni, F.; Merlini, L.; Scheffer, H.; Brunner, H. G.; Guicheney, P.; van Bokhoven, H. The Expanding Phenotype of POMT1 Mutations: From Walker-Warburg Syndrome to Congenital Muscular Dystrophy, Microcephaly, and Mental Retardation. Hum. Mutat. 2006, 27, 453-459.

(14) Balci, B.; Uyanik, G.; Dincer, P.; Gross, C.; Willer, T.; Talim, B.; Haliloglu, G.; Kale, G.; Hehr, U.; Winkler, J.; Topaloğlu, H. An Autosomal Recessive Limb Girdle Muscular Dystrophy (LGMD2) with Mild Mental Retardation Is Allelic to Walker-Warburg Syndrome (WWS) Caused by a Mutation in the POMT1 Gene. Neuromuscular Disord. 2005, 15, 271-275.

(15) Cormand, B.; Pihko, H.; Bayés, M.; Valanne, L.; Santavuori, P.; Talim, B.; Gershoni-Baruch, R.; Ahmad, A.; van Bokhoven, H.; Brunner, H. G.; Voit, T.; Topaloglu, H.; Dobyns, W. B.; Lehesjoki, A. E. Clinical and Genetic Distinction between Walker-Warburg Syndrome and Muscle-Eye-Brain Disease. Neurology 2001, 56, 1059-1069.

(16) Willer, T.; Prados, B.; Falcón-Pérez, J. M.; Renner-Müller, I.; Przemeck, G. K. H.; Lommel, M.; Coloma, A.; Valero, M. C.; de
Angelis, M. H.; Tanner, W.; Wolf, E.; Strahl, S.; Cruces, J. Targeted Disruption of the Walker-Warburg Syndrome Gene Pomt1 in Mouse Results in Embryonic Lethality. Proc. Natl. Acad. Sci. U.S.A. 2004, 101, 14126-14131.

(17) Rubio-Fernández, M.; Uribe, M. L.; Vicente-Tejedor, J.; Germain, F.; Susín-Lara, C.; Quereda, C.; Montoliu, L.; de La Villa, P.; Martín-Nieto, J.; Cruces, J. Impairment of Photoreceptor Ribbon Synapses in a Novel Pomt1 Conditional Knockout Mouse Model of Dystroglycanopathy. Sci. Rep. 2018, 8, No. 8543.

(18) Nishida, A.; Furukawa, A.; Koike, C.; Tano, Y.; Aizawa, S.; Matsuo, I.; Furukawa, T. Otx2 Homeobox Gene Controls Retinal Photoreceptor Cell Fate and Pineal Gland Development. Nat. Neurosci. 2003, 6, 1255-1263.

(19) Fischer, A. H.; Jacobson, K. A.; Rose, J.; Zeller, R. Hematoxylin and Eosin Staining of Tissue and Cell Sections. Cold Spring Harbor Protoc. 2008, 3, No. pdb.prot 4986.

(20) Haro, C.; Uribe, M. L.; Quereda, C.; Cruces, J.; Martín-Nieto, J. Expression in Retinal Neurons of Fukutin and FKRP, the Protein Products of Two Dystroglycanopathy-Causative Genes. Mol. Vision 2018, 24, 43-58.

(21) Uribe, M. L.; Haro, C.; Ventero, M. P.; Campello, L.; Cruces, J.; Martín-Nieto, J. Expression Pattern in Retinal Photoreceptors of POMGnT1, a Protein Involved in Muscle-Eye-Brain Disease. Mol. Vision 2016, 22, 658-673.

(22) Hüttl, S.; Michalakis, S.; Seeliger, M.; Luo, D. G.; Acar, N.; Geiger, H.; Hudl, K.; Mader, R.; Haverkamp, S.; Moser, M.; Pfeifer, A.; Gerstner, A.; Yau, K. W.; Biel, M. Impaired Channel Targeting and Retinal Degeneration in Mice Lacking the Cyclic Nucleotide-Gated Channel Subunit CNGB1. J. Neurosci. 2005, 25, 130-138.

(23) Boersema, P. J.; Raijmakers, R.; Lemeer, S.; Mohammed, S.; Heck, A. J. R. Multiplex Peptide Stable Isotope Dimethyl Labeling for Quantitative Proteomics. Nat. Protoc. 2009, 4, 484-494.

(24) Hassan, C.; Kester, M. G. D.; de Ru, A. H.; Hombrink, P.; Drijfhout, J. W.; Nijveen, H.; Leunissen, J. A. M.; Heemskerk, M. H. M.; Falkenburg, J. H. F.; van Veelen, P. A. The Human Leukocyte AntigenPresented Ligandome of B Lymphocytes. Mol. Cell. Proteomics 2013, 12, 1829-1843.

(25) Käll, L.; Canterbury, J. D.; Weston, J.; Noble, W. S.; MacCoss, M. J. Semi-Supervised Learning for Peptide Identification from Shotgun Proteomics Datasets. Nat. Methods 2007, 4, 923-925.

(26) Vizcaíno, J. A.; Csordas, A.; Del-Toro, N.; Dianes, J. A.; Griss, J.; Lavidas, I.; Mayer, G.; Perez-Riverol, Y.; Reisinger, F.; Ternent, T.; Xu, Q. W.; Wang, R.; Hermjakob, H. 2016 Update of the PRIDE Database and Its Related Tools. Nucleic Acids Res. 2016, 44, D447-D456.

(27) Kannan, R.; Sreekumar, P. G.; Hinton, D. R. Novel Roles for $\alpha$ Crystallins in Retinal Function and Disease. Prog. Retinal Eye Res. 2012, 31, 576-604.

(28) Forsythe, E.; Beales, P. L. Bardet-Biedl Syndrome. Eur. J. Hum. Genet. 2013, 21, 8-13.

(29) Bravo-Nuevo, A.; Walsh, N.; Stone, J. Photoreceptor Degeneration and Loss of Retinal Function in the C57BL/6-C2J Mouse. Invest. Ophthalmol. Visual Sci. 2004, 45, 2005-2012.

(30) Kuny, S.; Gaillard, F.; Sauvé, Y. Differential Gene Expression in Eyecup and Retina of a Mouse Model of Stargardt-like Macular Dystrophy (STGD3). Invest. Ophthalmol. Visual Sci. 2012, 53, 664675 .

(31) Valter, K.; Bisti, S.; Gargini, C.; di Loreto, S.; Maccarone, R.; Cervetto, L.; Stone, J. Time Course of Neurotrophic Factor Upregulation and Retinal Protection against Light-Induced Damage after Optic Nerve Section. Invest. Ophthalmol. Visual Sci. 2005, 46, $1748-1754$.

(32) Larsen, I. S. B.; Narimatsu, Y.; Joshi, H. J.; Yang, Z.; Harrison, O. J.; Brasch, J.; Shapiro, L.; Honig, B.; Vakhrushev, S. Y.; Clausen, H.; Halim, A. Mammalian O-Mannosylation of Cadherins and Plexins Is Independent of Protein O-Mannosyltransferases 1 and 2. J. Biol. Chem. 2017, 292, 11586-11598.

(33) de Bruijn, S. E.; Verbakel, S. K.; de Vrieze, E.; Kremer, H.; Cremers, F. P. M.; Hoyng, C. B.; Ingeborgh Van Den Born, L.; Roosing, S. Homozygous Variants in KIAA1549, Encoding a Ciliary Protein, Are 
Associated with Autosomal Recessive Retinitis Pigmentosa. J. Med. Genet. 2018, 55, 705-712.

(34) Williamson, R. A.; Henry, M. D.; Daniels, K. J.; Hrstka, R. F.; Lee, J. C.; Sunada, Y.; Ibraghimov-Beskrovnaya, O.; Campbell, K. P. Dystroglycan Is Essential for Early Embryonic Development: Disruption of Reichert's Membrane in Dag1-Null Mice. Hum. Mol. Genet. 1997, 6, 831-841.

(35) Holzfeind, P. J.; Grewal, P. K.; Reitsamer, Ha.; Kechvar, J.; Lassmann, H.; Hoeger, H.; Hewitt, J. E.; Bittner, R. E. Skeletal, Cardiac and Tongue Muscle Pathology, Defective Retinal Transmission, and Neuronal Migration Defects in the Large(Myd) Mouse Defines a Natural Model for Glycosylation-Deficient Muscle - Eye - Brain Disorders. Hum. Mol. Genet. 2002, 11, 2673-2687.

(36) Lee, Y.; Kameya, S.; Cox, Ga.; Hsu, J.; Hicks, W.; Maddatu, T. P.; Smith, R. S.; Naggert, J. K.; Peachey, N. S.; Nishina, P. M. Ocular Abnormalities in Largemyd and Largevls Mice, Spontaneous Models for Muscle, Eye, and Brain Diseases. Mol. Cell. Neurosci. 2005, 30, 160172.

(37) Liu, J.; Ball, S. L.; Yang, Y.; Mei, P.; Zhang, L.; Shi, H.; Kaminski, H. J.; Lemmon, V. P.; Hu, H. A Genetic Model for Muscle-Eye-Brain Disease in Mice Lacking Protein O-Mannose 1,2-N-Acetylglucosaminyltransferase (POMGnT1). Mech. Dev. 2006, 123, 228-240.

(38) Beedle, A. M.; Turner, A. J.; Saito, Y.; Lueck, J. D.; Foltz, S. J.; Fortunato, M. J.; Nienaber, P. M.; Campbell, K. P. Mouse Fukutin Deletion Impairs Dystroglycan Processing and Recapitulates Muscular Dystrophy. J. Clin. Invest. 2012, 122, 3330-3342.

(39) Omori, Y.; Araki, F.; Chaya, T.; Kajimura, N.; Irie, S.; Terada, K.; Muranishi, Y.; Tsujii, T.; Ueno, S.; Koyasu, T.; Tamaki, Y.; Kondo, M.; Amano, S.; Furukawa, T. Presynaptic Dystroglycan-Pikachurin Complex Regulates the Proper Synaptic Connection between Retinal Photoreceptor and Bipolar Cells. J. Neurosci. 2012, 32, 6126-6137.

(40) Satz, J. S.; Philp, A. R.; Nguyen, H.; Kusano, H.; Lee, J.; Turk, R.; Riker, M. J.; Hernández, J.; Weiss, R. M.; Anderson, M. G.; Mullins, R. F.; Moore, Sa.; Stone, E. M.; Campbell, K. P. Visual Impairment in the Absence of Dystroglycan. J. Neurosci. 2009, 29, 13136-13146.

(41) Orlandi, C.; Omori, Y.; Wang, Y.; Cao, Y.; Ueno, A.; Roux, M. J.; Condomitti, G.; de Wit, J.; Kanagawa, M.; Furukawa, T.; Martemyanov, K. A. Transsynaptic Binding of Orphan Receptor GPR179 to Dystroglycan-Pikachurin Complex Is Essential for the Synaptic Organization of Photoreceptors. Cell Rep. 2018, 25, 130-145.

(42) Gomez Toledo, A.; Raducu, M.; Cruces, J.; Nilsson, J.; Halim, A.; Larson, G.; Rüetschi, U.; Grahn, A. O-Mannose and O-N-Acetyl Galactosamine Glycosylation of Mammalian $\alpha$-Dystroglycan Is Conserved in a Region-Specific Manner. Glycobiology 2012, 22, $1413-1423$.

(43) Vester-Christensen, M. B.; Halim, A.; Joshi, H. J.; Steentoft, C.; Bennett, E. P.; Levery, S. B.; Vakhrushev, S. Y.; Clausen, H. Mining the O-Mannose Glycoproteome Reveals Cadherins as Major O-Mannosylated Glycoproteins. Proc. Natl. Acad. Sci. U.S.A. 2013, 110, 2101821023.

(44) Yoshida-Moriguchi, T.; Yu, L.; Stalnaker, S.; Sarah Davis, S. H.; Kunz, S.; Madson, M.; Oldstone, M. B. A.; Schachter, H.; Wells, L.; Campbell, K. P. O-Mannosyl Phosphorylation of Alpha-Dystroglycan Is Required for Laminin Binding. Science 2010, 327, 88-92.

(45) Larsen, I. S. B.; Narimatsu, Y.; Joshi, H. J.; Siukstaite, L.; Harrison, O. J.; Brasch, J.; Goodman, K. M.; Hansen, L.; Shapiro, L.; Honig, B.; Vakhrushev, S. Y.; Clausen, H.; Halim, A. Discovery of an OMannosylation Pathway Selectively Serving Cadherins and Protocadherins. Proc. Natl. Acad. Sci. U.S.A. 2017, 114, 11163-11168.

(46) Yamashita, S.; Takeshima, H.; Matsumoto, F.; Yamasaki, K.; Fukushima, T.; Sakoda, H.; Nakazato, M.; Saito, K.; Mizuguchi, A.; Watanabe, T.; Ohta, H.; Yokogami, K. Detection of the KIAA1549BRAF Fusion Gene in Cells Forming Microvascular Proliferations in Pilocytic Astrocytoma. PLoS One 2019, 14, No. e0220146.

(47) Gao, H.; Hollyfield, J. G. Basic Fibroblast Growth Factor: Increased Gene Expression in Inherited and Light-Induced Photoreceptor Degeneration. Exp. Eye Res. 1996, 62, 181-190.

(48) Gao, H.; Hollyfield, J. G. Basic Fibroblast Growth Factor in Retinal Development: Differential Levels of BFGF Expression and
Content in Normal and Retinal Degeneration (Rd) Mutant Mice. Dev. Biol. 1995, 169, 168-184.

(49) Roche, S. L.; Wyse-Jackson, A. C.; Byrne, A. M.; Ruiz-Lopez, A. M.; Cotter, T. G. Alterations to Retinal Architecture Prior to Photoreceptor Loss in a Mouse Model of Retinitis Pigmentosa. Int. J. Dev. Biol. 2016, 60, 127-139.

(50) Coorey, N. J.; Shen, W.; Zhu, L.; Gillies, M. C. Differential Expression of IL-6/Gp130 Cytokines, Jak-STAT Signaling and Neuroprotection after Müller Cell Ablation in a Transgenic Mouse Model. Invest. Ophthalmol. Visual Sci. 2015, 56, 2151-2161.

(51) Jiang, K.; Wright, K. L.; Zhu, P.; Szego, M. J.; Bramall, A. N.; Hauswirth, W. W.; Li, Q.; Egan, S. E.; McInnes, R. R. STAT3 Promotes Survival of Mutant Photoreceptors in Inherited Photoreceptor Degeneration Models. Proc. Natl. Acad. Sci. U.S.A. 2014, 111, E5716-E5723. 